\title{
WILLIAM R. ANDERSON
}

\author{
(25 De SePtiembre de 1942 - 2 de NOVIeMBre de 2013)
}

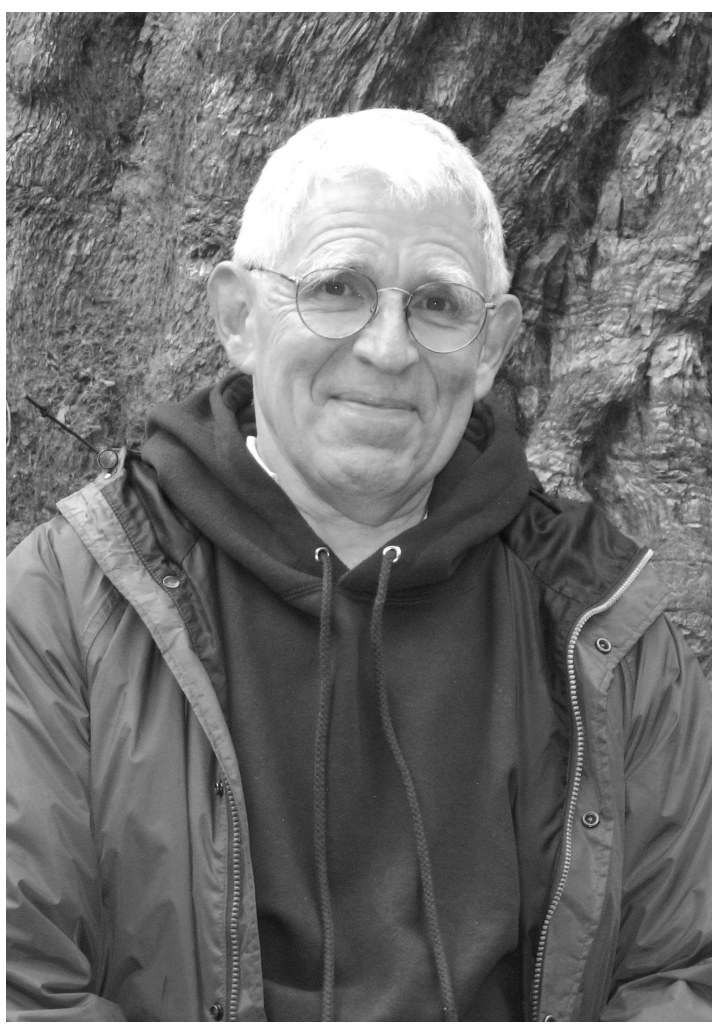

W illiam Russell Anderson nació en Tucson, Arizona en 1942 y falleció en Ann Arbor, Michigan el 2 de Noviembre de 2013. Sus padres fueron John L. y Eleanor (McCaddon) Anderson. Siendo estudiante de posgrado conoció a Christiane Eva Seidenschnur, con quien contrajo matrimonio en 1967 y tuvo dos hijos: Russell y Rebecca Christiane. Más adelante, Chris y Bill Anderson formaron un formidable equipo de trabajo.

Un experto en sistemática y florística y un erudito en nomenclatura botánica a quien muchos recurríamos para resolver dudas, el Dr. Anderson obtuvo su Licenciatura en ciencias de la Universidad de Duke en 1964 y los grados de Maestría (1965) y Doctorado (1971) de la Universidad de Michigan en Ann Arbor, estos últimos bajo la guía del Dr. Rogers McVaugh.

Después de graduarse en Michigan, inició su carrera en 1971 como curador asociado en el New York Botanical Garden, donde pronto se posicionó como el especialista mundial en Malpighiaceae. En 1974 regresó a la Universidad de Michigan contratado como profesor e investigador en el Departmento de Botánica, siendo luego director del Herbario entre 1986 y 1999. Después de una productiva carrera se retiró en 2002, pero hasta poco antes de su muerte permaneció activo en investigación como Profesor Emérito de botánica y Curador Emérito de plantas vasculares del herbario $\mathrm{MICH}$.

Fue un estudioso de la taxonomía de plantas vasculares, particularmente de Malpighiaceae, una familia primordialmente Neotropical, una de las razones por las que su interés estuvo enfocado en gran parte hacia la flora de Latinoamérica. Desarrolló monografías y revisiones taxonómicas, descripciones de nuevos géneros y especies, contribuciones en floras, combinaciones nomenclaturales, estudios de biología reproductiva, análisis de cariotipos y estudios filogenéticos. Los resultados de sus estudios sobre la autofecundación en las flores cleistógamas de Gaudichaudia fueron publicados en la revista Science y le valieron un reconocimiento en la reunión anual de 1975 de la Sociedad Americana de Taxónomos de Plantas (American Society of Plant Taxonomists). Publicó más de 80 artículos científicos y muchas contribuciones en diversos proyectos florísticos desde Arizona hasta Uruguay. Su trabajo más reciente (2013), “Origins of Mexican Malpighiaceae", estuvo dedicado a nuestro país.

El Dr. Anderson fue además el editor general de ocho volúmenes de la Flora NovoGaliciana desarrollada por el Dr. Rogers McVaugh, su antiguo mentor y luego colega en la Universidad de Michigan. Al promover y conseguir financiamiento para la publicación de la Flora Novo-Galiciana, con detallados tratamientos de las familias botánicas más diversas del occidente de México, hizo una importantísima aportación al conocimiento de la flora de nuestro país. 
Su trabajo de campo en México, Centro y Sudamérica resultó en colectas de material de excepcional calidad. Con evidente placer, Bill recordaba sus viajes a México con su colega y esposa Chris y con entrañables amigos botánicos como los doctores McVaugh, Rzedowski y Villarreal de Puga, entre otros.

Colaboró con Chris Anderson en la creación de un sitio web para describir e ilustrar bellamente los géneros de Malpighiaceae (http://herbarium.lsa.umich.edu/malpigh/) con apoyo de la National Science Foundation, y con el Dr. Charles C. Davis para elucidar la filogenia genérica y supragenérica de la familia a través de datos moleculares y morfológicos.

El Dr. Anderson fue presidente de la American Society of Plant Taxonomists en 1993-1994 y apoyó de diversas maneras a esa asociación a lo largo de varias décadas. Participó además en diversos comités como el de espermatofitas de la International Association for Plant Taxonomy, el Steering Committee del proyecto Species Plantarum y el Steering Committee de la Systematics Agenda 2000. Durante su carrera, recibió numerosas distinciones y reconocimientos, entre los que están: la University of Michigan Faculty Recognition Award, la Robert Allerton Award por Excelencia en Botánica Tropical, del National Tropical Botanical Garden (2007) y la Asa Gray Award de la American Society of Plant Taxonomists (2008). Para honrar su papel como mentor de numerosos estudiantes a través de su carrera, colegas y antiguos estudiantes establecieron en 2002 el Fondo William R. Anderson de la ASPT de apoyo a estudiantes graduados para desarrollar investigación.

Carismático, culto y brillante, apasionado amante de la ópera, Bill Anderson fue un personaje complejo. Era perfeccionista y muy exigente, tanto con su propio trabajo como con el de los demás. Genuino, directo y claro sin tapujos, a veces irónico, llegaba a ser incómodo y hasta intimidante para algunos, pero su personalidad destacaba por su lucidez deslumbrante, su conocimiento enciclopédico, su agudo sentido del humor y su risa fácil.

Con extraordinaria generosidad, Bill apoyó siempre de manera irrestricta a los visitantes que consultaban el herbario MICH y a quienquiera que le solicitaba información taxonómica o nomenclatural. Tenía una permanente disposición para ayudar y era un perfecto anfitrión en el herbario y fuera de él. ¿Cómo olvidar su amplia sonrisa al recibirnos después de una espera de horas en el aeropuerto debido a un problema en nuestro viaje? Somos muchos los que recordaremos con gratitud y cariño todas las gentilezas recibidas de él y de su esposa Chris, con quien estuvo casado por 46 años. Le sobreviven ella y su hija Rebecca. Descanse en paz.

Esta nota se basa en parte en el obituario escrito por Paul Berry (2013) y en el escrito de Thomas Daniel and Stephen Weller (2009). Agradezco a los doctores Chris Anderson, Tony Reznizek, Martha González y J. Rzedowski por datos y comentarios.

\section{Referencias}

Anderson W.R. 2013. Origins of Mexican Malpighiaceae. Acta Botanica Mexicana 104:107-156. Berry P. 2013. In memoriam: Emeritus Professor of Botany William Anderson. University of Michigan. 7 Nov 2013. https://www.lsa.umich.edu/eeb/news/ci.inmemoriamemeritusprofess orofbotanywilliamandersonwed27nov2013_ci.detail (consultado 18 Dic 2013)

Daniel T.F. y Weller S.G. 2009. William R. Anderson-Recipient of the 2008 Asa Gray Award. Systematic Botany 34:1-3.

M. Socorro González Elizondo

Herbario CIIDIR

Instituto Politécnico Nacional 